\title{
Pengaruh Kecepatan Udara dan Debit Bahan Bakar pada Pembakaran Burner Berbahan Bakar Oli Bekas
}

\author{
Khabibbullah Enggal Mahardhika ${ }^{1, a)}$, Deri Teguh Santoso ${ }^{2, b)}, \operatorname{Kardiman}^{3, c)}$ \\ 1,2,3Program Studi Teknik Mesin Universitas Singaperbangsa Karawang, \\ Jl. HS. Ronggowaluyo, Telukjambe Timur, Karawang-Jawa Barat, 41361 \\ a)1610631150073@student.unsika.ac.id, ${ }^{\text {b) }}$ deri.teguh@ft.unsika.ac.id, ${ }^{c}$ kardiman@ft.unsika.ac.id,
}

\begin{abstract}
Abstrak
Penggunaan pelumas meningkat seiring berkembangnya mesin yang digunakan, namun daur ulang pelumas bekas masih belum optimal. Penelitian kali ini akan dilakukan pengujian pada burner yang menggunakan oli bekas sebagai bahan bakar, dengan pemanasan awal pada oli bekas yang bertujuan untuk memudahkan proses pembakaran burner, selain itu akan dilakukan eksperimen mengenai kecepatan udara dan debit bahan bakar terhadap temperatur, panjang lidah api, dan waktu pembakaran. Pengujian dilakukan dengan variasi kecepatan udara $2,0 \mathrm{~m} / \mathrm{s}, 2,2 \mathrm{~m} / \mathrm{s}$, dan $2,4 \mathrm{~m} / \mathrm{s}$ dengan debit bahan bakar 1,7 $\times 10^{-7} \mathrm{~m}^{3} / \mathrm{s}, 2,4 \times 10^{-7} \mathrm{~m}^{3} / \mathrm{s}$, dan $4,8 \times 10^{-7} \mathrm{~m}^{3} / \mathrm{s}$. Dari penelitian yang telah dilakukan dapat disimpulkan bahwa kecepatan udara yang semakin besar berpengaruh pada peningkatan temperatur, dan panjang lidah api. Sedangkan waktu pembakaran menjadi semakin cepat seiring besarnya kecepatan udara. Serta semakin besar debit aliran berpengaruh pada peningkatan temperatur dan panjang lidah api, namun tidak berpengaruh pada kenaikan waktu pembakaran.
\end{abstract}

Kata kunci: burner, oli bekas, pre-heating, kecepatan udara, debit bahan bakar

\begin{abstract}
The use of lubricants increases as machines are used, but recycling of used lubricants is still not optimal. This research will test the burner with used oil as a fuel, by preheating used oil which aims to facilitate the burner combustion process, besides that, experiments will be carried out regarding air velocity and fuel discharge against temperature, length of the flame, and burning time. Tests were carried out with air velocity variations of $2.0 \mathrm{~m} / \mathrm{s}, 2.2 \mathrm{~m} / \mathrm{s}$, and $2.4 \mathrm{~m} / \mathrm{s}$ with a fuel discharge of $1,7 \times 10^{-7} \mathrm{~m}^{3} / \mathrm{s}, 2,4 \times 10^{-7} \mathrm{~m}^{3} / \mathrm{s}$, and $4,8 \times 10^{-7} \mathrm{~m}^{3} / \mathrm{s}$. From the research, it can be concluded that the greater the air velocity has an effect on the increase in temperature and the length of the flame. Meanwhile, the combustion time becomes faster as the air velocity increases. As well as the greater the flow rate has an effect on the increase in temperature and flame length, but does not affect the increase in combustion time.
\end{abstract}

Keywords: burner, used oil, pre-heating, air velocity, fuel discharge

\section{PENDAHULUAN}

Limbah oli bekas merupakan salah satu limbah jenis B3 yang jumlahnya semakin banyak akibat dari peningkatan mesin-mesin baik mesin produksi maupun mesin dari kendaraan bermotor. Oli bekas dapat digunakan sebagai bahan bakar pada burner, yaitu alat yang berfungsi menjadi pembakar dan pemanas seperti pada kompor atau tungku. Agar pembakaran pada burner dapat berfungsi dengan baik, burner memerlukan udara, dan bahan bakar yang dicampurkan sedemikian rupa sehingga dapat terbakar. Namun nyala burner ini dipengaruhi oleh beberapa faktor seperti kecepatan udara, dan debit bahan bakar yang mengalir menuju ruang pembakaran, serta pencampuran bahan bakar seperti oli bekas dengan minyak jelantah dan minyak tanah.

Beberapa penelitan tentang penggunaan oli sebagai bahan bakar pada burner dengan mencampur oli bekas dan minyak tanah, kemudian diinjeksikan ke dalam atomizing burner. Hasil penelitian menunjukkan bahwa semakin tinggi kadar campuran minyak tanah akan menurunkan viskositas serta titik nyala bahan bakar [1].
Selanjutnya telah dilakukan penelitian dengan mencampurkan oli bekas dan minyak jelantah sebagai bahan bakar, dari hasil penelitiannya menunjukkan bahwa peningkatan tekanan dan pencampuran minyak jelantah tidak berpengaruh terhadap penambahan panjang lidah api, apabila dibandingkan dengan penggunaan oli bekas saja sebagai bahan bakar [2]. Kemudian juga penelitian tentang pemanfaatan oli bekas sebagai bahan bakar burner. Dari penelitian didapatkan permasalahan utama pemanfaatan oli bekas sebagai bahan bakar adalah viskositas oli bekas yang terlalu tinggi, sehingga sulit untuk dikabutkan dan mencapai kondisi pembakaran yang baik [3].

Berdasarkan dari penelitian sebelumnya menggunakan berbagai jenis campuran bahan bakar serta tekanan yang bervariasi, maka pada penelitian ini akan dilakukan analisis pengaruh kecepatan dan debit bahan bakar terhadap temperatur, panjang lidah api dan waktu pembakaran. 


\section{LANDASAN TEORI}

\section{A. Burner}

Burner adalah sebuah alat untuk menghasilkan api untuk memanaskan benda dengan menggunakan bahan bakar baik padat, cair maupun gas. Agar dapat menghasilkan pembakaran sempurna, maka burner membutuhkan udara untuk untuk dicampur dengan bahan bakar [4].

Karena menggunakan limbah oli bekas sebagai bahan bakar, maka ada beberapa faktor yang harus dipertimbangkan agar burner dapat bekerja dengan sempurna, dimana oli bekas merupakan fluida dengan titik flash point yang tinggi yaitu pada temperatur $204^{\circ} \mathrm{C}$, temperatur pembakaran yang tinggi ini dapat mempersulit mekanisme pembakaran. Oleh sebab itu, pada penelitian kali ini bahan bakar yang akan mengalami proses pemanasan awal pada rentang temperatur $100-110^{\circ} \mathrm{C}$.

\section{B. Oli Bekas}

Oli bekas adalah oli atau pelumas yang sudah pernah digunakan, oli ini berasal dari mesin-mesin industri dan mesin kendaraan bermotor seperti sepeda motor, dan mobi. Karakteristik oli bekas berbeda dengan oli baru, seperti warna dan kekentalan yang berubah akibat pemanasan dan gesekan saat melakukan proses pelumasan. Oli yang telah digunakan dalam waktu cukup lama akan mengalami perubahan komposisi atau susunan kimia, selain itu juga akan mengalami perubahan sifat fisis, maupun mekanis. Hal ini disebabkan karena pengaruh tekanan dan suhu selama penggunaan dan juga kotoran-kotoran yang bercampur dengan pelumas [5].

\section{Aliran Fluida}

Pada aliran fluida bahan bakar, terdapat beberapa hal yang diperlukan, yaitu persamaan bernoulli, dan persamaan kontinuitas yang berkaitan dengan kecepatan aliran dan luas penampang yang dialiri oleh fluida. Persamaan Bernoulli adalah suatu persamaan yang menjelaskan berbagai hal yang berkaitan dengan kecepatan, tinggi permukaan zat cair dan tekanannya. Pada penelitian kali ini digunakan persamaan Bernoulli untuk menghitung kecepatan aliran yang mengalir pada tangki bahan bakar yang diisi oli bekas [6].

$v=\sqrt{2 g \Delta h}$

Keterangan:

$\mathrm{P}=$ Tekanan $(\mathrm{Pa})$

$\rho=$ Massa Jenis $\left(\mathrm{kg} / \mathrm{m}^{3}\right)$

$\mathrm{v}=$ Kecepatan aliran fluida $(\mathrm{m} / \mathrm{s})$

$\mathrm{g}=$ Percepatan gravitasi $\left(\mathrm{m} / \mathrm{s}^{2}\right)$

$\Delta \mathrm{h}=$ Selisih ketinggian permukaan fluida $(\mathrm{m})$

Persamaan kontinuitas menyatakan bahwa debit fluida yang memasuki pipa yang sama dengan debit fluida yang keluar dari pipa. Faktor yang berpengaruh pada persamaan kontinuitas adalah kecepatan aliran dan luas penampang. Debit merupakan jumlah volume fluida per satuan waktu yang mengalir pada luas penampang tertentu, maka debit aliran dapat dihitung dengan menggunakan persamaan 2 [6].

$\mathrm{Q}=\mathrm{V} \cdot \mathrm{A}$

Keterangan:

$\mathrm{Q}=$ Debit aliran $\left(\mathrm{m}^{3} / \mathrm{s}\right)$

$\mathrm{V}=$ Kecepatan aliran $(\mathrm{m} / \mathrm{s})$

$\mathrm{A}=$ Luas Penampang $\left(\mathrm{m}^{2}\right)$

\section{METODE PENELITIAN}

\section{A. Alat dan Bahan}

Alat yang digunakan pada penelitian ini merupakan alat burner yang telah dirancang sebelumnya, seperti ditunjukkan pada Gambar 1.

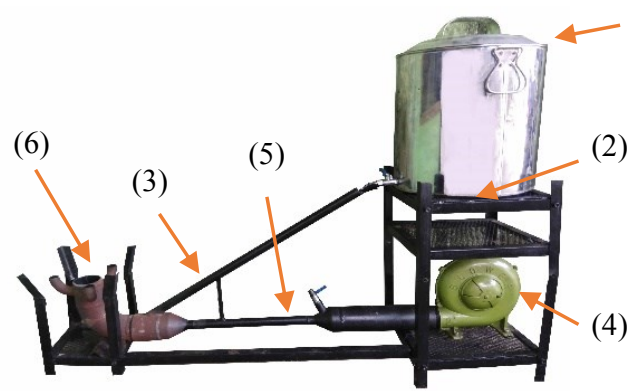

Gambar 1. Alat burner berbahan bakar oli

Gambar 1 merupakan alat burner berbahan bakar oli berkapasitas 10 liter, dengan daya blower $150 \mathrm{~W}$ dan diameter tungku pembakaran $0,054 \mathrm{~m}$. Prinsip kerja alat ini dimulai dengan memasukkan oli pada tangki bahan bakar (1), lalu dipanaskan menggunakan heater (2) hingga mencapai temperatur $100-110^{\circ} \mathrm{C}$, selanjutnya oli dialirkan melalui pipa (3), setelah itu blower (4) mengalirkan udara berkecepatan melalui pipa (5) ke tungku pembakaran (6). Sedangkan bahan pada penelitian ini adalah limbah oli yang didapat dari pengepul oli bekas di Kabupaten Karawang.

\section{B. Kondisi Awal Pengujian}

Pengujian dilakukan menggunakan volume oli bekas $100 \mathrm{ml}$, dan akan memvariasikan kecepatan udara 2,0 m/s, $2,2 \mathrm{~m} / \mathrm{s}$ dan $2,4 \mathrm{~m} / \mathrm{s}$ yang masuk ke tungku pembakaran, selain itu pengujian yang akan diamati adalah pengaruh debit bahan bakar $0,0016 \mathrm{~m}^{3} / \mathrm{s}, 0,0024 \mathrm{~m}^{3} / \mathrm{s}$ dan 0,0048 $\mathrm{m}^{3} / \mathrm{s}$. Hasil perhitungan mengenai debit aliran bahan bakar ditunjukkan pada Tabel 1. Debit Aliran

Tabel 1. Debit Aliran

\begin{tabular}{|c|c|c|}
\hline $\begin{array}{c}\text { Bukaan } \\
\text { Katup }\end{array}$ & $\begin{array}{l}\text { Kecepatan x Luas } \\
\text { Permukaan (V.A) }\end{array}$ & $\begin{array}{c}\text { Debit Aliran } \\
\text { (Q) }\end{array}$ \\
\hline 1 & $0,0246 \mathrm{~m} / \mathrm{s} \times 6.54 \times 10^{-6} \mathrm{~m}^{2}$ & $\begin{array}{c}1,7 \times 10^{-7} \\
\mathrm{~m}^{3} / \mathrm{s}\end{array}$ \\
\hline 2 & $0,0246 \mathrm{~m} / \mathrm{s} \times 9,8 \times 10^{-6} \mathrm{~m}^{2}$ & $\begin{array}{c}2,4 \times 10^{-7} \\
\mathrm{~m}^{3} / \mathrm{s}\end{array}$ \\
\hline 3 & $0,0246 \mathrm{~m} / \mathrm{s} \times 1,96 \times 10^{-5} \mathrm{~m}^{2}$ & $\begin{array}{c}4,8 \times 10^{-7} \\
\mathrm{~m}^{3} / \mathrm{s}\end{array}$ \\
\hline
\end{tabular}




\section{Pengujian}

Pengujian pengaruh debit bahan bakar dilakukan dengan 3 variasi bukaan katup, seperti ditunjukkan pada Gambar 2. variasi bukaan katup bahan bakar.

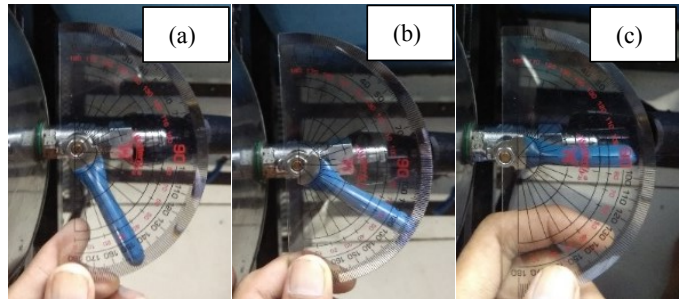

Gambar 2. Variasi bukaan katup (a) sudut $30^{\circ}$, (b) sudut $60^{\circ},(\mathrm{c})$ sudut $90^{\circ}$

Dilihat dari Gambar 2. (a) sudut $30^{\circ}$ katup berada pada bukaan 1 menghasilkan debit aliran bahan bakar 1,7 $\times 10^{-7}$ $\mathrm{m}^{3} / \mathrm{s}$, (b) sudut $60^{\circ}$ katup berada pada bukaan 2 menghasilkan debit aliran bahan bakar 2,4 $\times 10^{-7} \mathrm{~m}^{3} / \mathrm{s}$ dan (c) sudut $90^{\circ}$ katup berada pada bukaan 3 menghasilkan debit aliran bahan bakar 4,8 $\times 10^{-7} \mathrm{~m}^{3} / \mathrm{s}$.

Untuk menentukan kecepatan udara pada blower, pengukuran dilakukan dengan anemometer digital yang berfungsi mengukur kecepatan udara yang masuk menuju tungku pembakaran, pengukuran tersebut ditunjukkan pada Gambar 3. Variasi kecepatan udara blower.

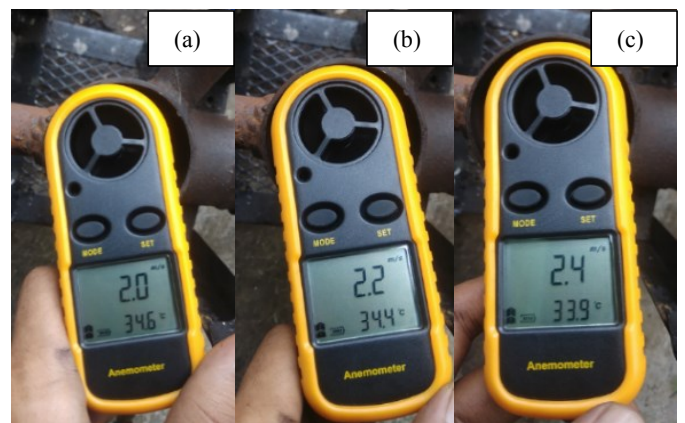

Gambar 3. Variasi kecepatan udara blower (a) 2,0 m/s, (b) $2,2 \mathrm{~m} / \mathrm{s}$ dan (c) $2,4 \mathrm{~m} / \mathrm{s}$

Dilihat dari Gambar 3. (a) kecepatan udara blower 2,0 $\mathrm{m} / \mathrm{s}$, (b) kecepatan udara blower 2,2 $\mathrm{m} / \mathrm{s}$ dan (c) kecepatan udara blower $2,2 \mathrm{~m} / \mathrm{s}$. Selain itu diperlukan beberapa variabel yang diatur homogen pada setiap pengujan, yaitu volume bahan bakar $100 \mathrm{ml}$ dan temperatur pre-heating $100-110^{\circ} \mathrm{C}$.

\section{HASIL DAN PEMBAHASAN}

Dari pengujian pengaruh kecepatan udara dihasilkan temperatur, panjang lidah api, dan waktu pembakaran seperti terlihat pada Gambar 4. Hasil pengujian burner dengan variasi kecepatan udara terhadap temperatur, panjang lidah api dan waktu pembakaran

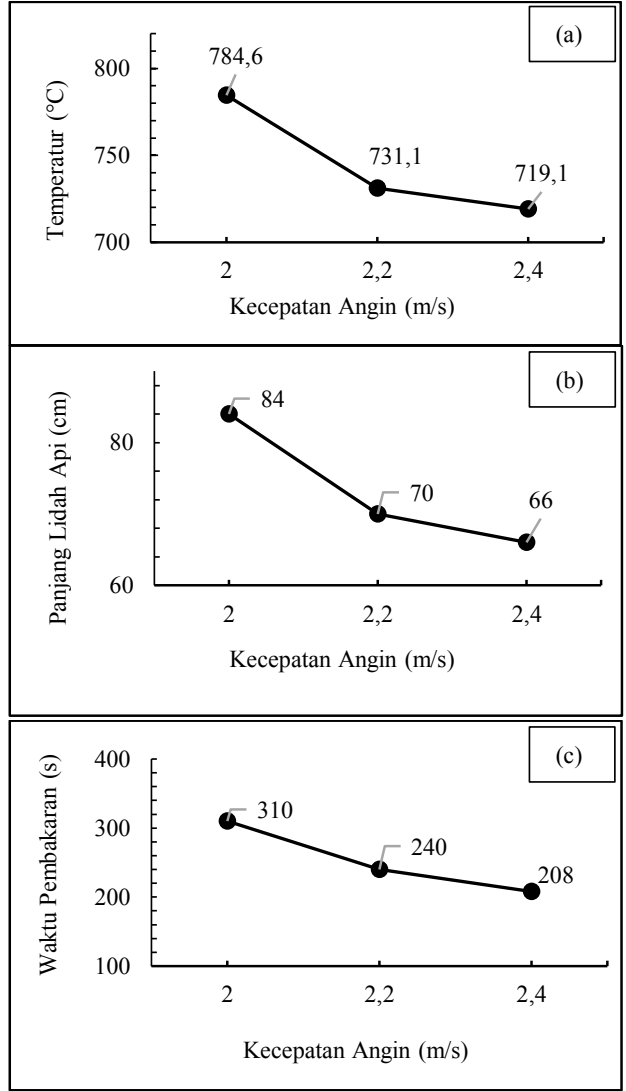

Gambar 4. Hasil pengujian burner dengan variasi kecepatan udara terhadap (a) temperatur, (b) panjang lidah api dan (c) waktu pembakaran

Berdasarkan Gambar 4. Hasil pengujian burner dengan variasi kecepatan udara terhadap temperatur, panjang lidah api, dan waktu pembakaran menunjukkan bahwa seiring dengan peningkatan kecepatan udara blower berpengaruh pada penurunan (a) temperatur, (b) panjang lidah api, dan (c) waktu pembakaran.

Hal ini disebabkan oleh semakin besar kecepatan fluida, maka proses pencampuran udara dan bahan bakar menjadi tidak sempurna, sehingga bahan bakar terbawa keluar oleh udara sebelum terjadi proses karburasi. Bahan bakar yang belum terkaburasi dengan baik mengakibatkan penurunan temperatur dan waktu pembakaran menjadi lebih singkat. Selain itu besarnya kecepatan udara mengakibatkan panjang lidah api menurun.

Pada penelitian dengan judul Pengaruh Variasi Kecepatan Udara Terhadap Unjuk Kerja Fluidized Bed dengan Distributor Udara Jenis Plat, dinyatakan bahwa seiring meningkatnya kecepatan udara akan menyebabkan peningkatan temperatur dan panjang lidah api [7]. Sedangkan pada pengujian ini, temperatur yang dihasilkan menurun seiring peningkatan kecepatan udara. Kemudian pada penilitian dengan judul Pengaruh Laju Aliran Udara Terhadap Karakteristik Pembakaran Biobriket dari Limbah Penggilingan Padi (Sekam) menyimpulkan jika peningkatan keceparan aliran udara akan berpengaruh pada penurunan temperatur nyala [8].

Hasil pengujian mengenai pengaruh debit bahan bakar terhadap temperatur, panjang lidah api, dan waktu pembakaran dapat dilihat pada Gambar 5. Hasil pengujian 
burner dengan variasi debit aliran bahan bakar (bukaan katup) terhadap temperatur, panjang lidah api dan waktu pembakaran.

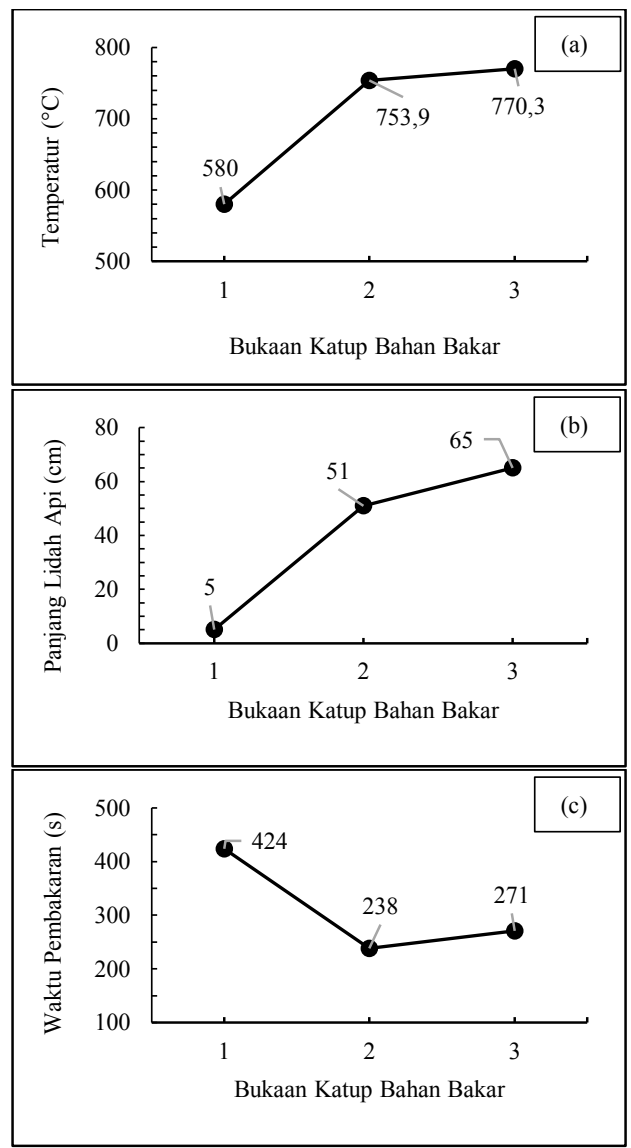

Gambar 5. Hasil pengujian burner dengan variasi debit aliran bahan bakar (bukaan katup) terhadap (a) temperatur, (b) panjang lidah api dan (c) waktu pembakaran

Dari Gambar 5. hasil pengujian burner dengan variasi debit aliran bahan bakar (bukaan katup) terhadap temperatur, panjang lidah api dan waktu pembakaran. dapat dilihat bahwa peningkatan debit aliran berpengaruh pada peningkatan temperatur, dan panjang lidah api. Namun pada bukaan katup 1 menunjukkan waktu pembakaran terlama, hal ini membuktikan bahwa dengan debit aliran rendah, dan kecepatan udara maksimum berpengaruh pada peningkatan waktu pembakaran menjadi lebih lama. Selain itu, karena massa jenis oli bekas lebih besar dibandingkan udara mengakibatkan udara dengan kecepatan tinggi dapat membuat proses karburasi bahan bakar menjadi lebih baik.

Sedangkan pada bukaan katup 2 terjadi penurunan waktu pembakaran, dan pada bukaan katup 3 terjadi kenaikan waktu pembakaran. Hal ini disebabkan karena banyaknya fluida bahan bakar yang masuk ke ruang pengkabutan, proses pengkabutan dan pembakaran menjadi tidak sempurna karena perbandingan bahan bakar pada ruang pembakaran terlalu banyak sedangkan udara yang masuk bernilai tetap.

Pada penelitian dengna judul Pengaruh Variasi Debit Aliran Terhadap Karakteristik Api Pembakaran Difusi
LPG dan CNG menyatakan bahwa seiring meningkatnya debit aliran bahan bakar akan berdampak pada peningkatan ketinggian panjang lidah api [9].

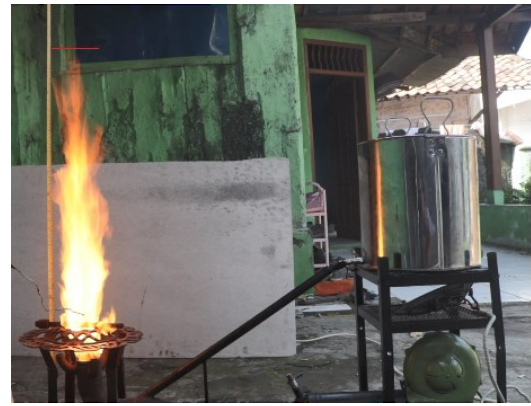

Gambar 6. Nyala api secara visual pada pembakaran burner

Dapat dilihat pada Gambar 6. Nyala api secara visual yang dihasilkan pada pembakaran burner terlihat berwarna merah kekuningan pada setiap variabel yang diuji. Warna nyala dipengaruhi oleh proses pembakaran yang tidak sempurna, hal ini disebabkan oleh kandungan senyawa karbon pada oli bekas sangat jenuh, sehingga memerlukan kadar oksigen yang lebih banyak untuk dapat melakukan reaksi pembakaran secara sempurna. Berbeda pada proses pembakaran gas LPG, dimana reaksi pembakaran yang terjadi merupakan reaksi pembakaran stoikiometri atau pembakaran sempurna sehingga dapat menghasilkan api yang berwarna biru.

\section{KESIMPULAN}

Dari penelitian yang telah dilakukan dapat disimpulkan bahwa kecepatan udara yang semakin besar berpengaruh pada peningkatan temperatur, dan panjang lidah api. Sedangkan waktu pembakaran semakin cepat seiring besarnya kecepatan udara.

Pada pengujian mengenai pengaruh debit bahan bakar, didapat bahwa kenaikan debit aliran berpengaruh pada peningkatan temperatur dan panjang lidah api. namun tidak berpengaruh pada kenaikan waktu pembakaran.

\section{REFERENSI}

[1] W. P. Raharjo, "Pemanfaatan Oli Bekas Dengan Pencampuran Minyak Tanah Sebagai Bahan Bakar Pada Atomizing Burner," Jurnal Penelitian Sains dan Teknologi, vol. 10, pp. 156-168, 2009.

[2] A. Agus, Rancang Bangun Dan Uji Performa Alat Burner Babington Dengan Menggunakan Bahan Bakar Oli Bekas Dan Minyak Jelantah, Palembang: Program Studi Teknik Mesin, Universitas Iba Palembang, 2014.

[3] A. K. Shaha, Combustion Engineering and Fuel Technology, Oxford: Oxford and IBH Publishing Company, 2007.

[4] V. Raghavan, Combustion Technology Essential of Flames and Burners, United Kingdom: John Wiley \& Sons, Ltd, 2016.

[5] R. Prasaji, "Pemanfaatan Kombinasi Fly Ash Batubara, Alkilbenzenesulfonat, dan Zeolit Pada Penjernihan Minyak Pelumas Bekas Dengan Metode Penjerapan," Jurnal Teknologi Kimia dan Industri, vol. 2, no. 4, pp. 1-7, 2013. 
[6] Ridwan, Mekanika Fluida Dasar, Jakarta: Penerbit Gunadarma, 1999.

[7] T. P. Yuono, Pengaruh Variasi Kecepatan Udara Terhadap Unjuk Kerja Fluidized Bed dengan Distributor Udara Jenis Plat, Surakarta: Universitas Muhammadiyah Surakarta, 2017.

[8] R. S. C. L. A. Laifa Rahmawati, "Pengaruh Laju Aliran Udara Terhadap Karakterisik Pembakaran Biobriket dari Limbah Penggilingan Padi (Sekam)," Pelita, vol. V, no. 2, 2010.

[9] N. A. M. A. F. Angga Dwinanda, "Pengaruh Variasi Debit Aliran Terhadap Karakteristik Api Pembakaran Difusi LPG dan CNG," Proteksion, vol. 3, no. 2, pp. 11-14, 2019. 